\title{
Evaluation of the Environmental Impacts Assessment (EIA) System in Lao PDR
}

\author{
Sengdeuane Wayakone*, Inoue Makoto \\ National University of Laos, Office of International Relations, Vientiane, Laos. \\ Email: "s_wayakone@yahoo.com \\ Received October $9^{\text {th }}$, 2012; revised October 31 ${ }^{\text {st }}$, 2012; accepted November $29^{\text {th }}, 2012$
}

\begin{abstract}
This study explores and seeks to explain the EIA procedures practice gap in Lao PDR. It reviews the literature and studies EIA legislation, administrative procedures, guidelines, and relevant documents by using a model proposed by Leu et al. (1996) and applying criteria proposed by Wood (1995) to evaluate the performance of EIA systems. Key EIA legislation in Lao PDR has many strengths, but also major weaknesses: Inadequate planning procedures, no secondary regulations, few trained and skilled personnel, inadequate public consultation, lack of environmental data, weak follow-up and monitoring, and no enforcement machinery. Additionally, the EIA approval procedure is very bureaucratic and easily derailed by political and economic pressures. In addition, coordination among EIA proponents, consultants, concerned ministries, local authorities, planners, and decision-makers is generally weak. This delays decision-making and hinders implementation of environmental regulations. Thus, procedures and evaluation are not always performed well. EIAs are more a project justification tool than a project planning tool for sustainable development. We conclude with recommendations to strengthen the system, such as improving capacity building, implementing an EIA consultants' accreditation system, ensuring effective public participation and access to EIA reports, applying systematic EIAs, reviewing criteria, and promoting environmental awareness.
\end{abstract}

Keywords: Environmental Impact Assessment; Lao PDR; Strength and Weakness; Procedures and Practices

\section{Introduction}

The environmental impact assessment (EIA), which is one of the environmental management tools established in many countries to ensure environmental protection [1], is a process whereby the potential environmental impacts of a proposed development are assessed at an early stage. Hence, significant impacts and measures to mitigate them can be identified, irreversible damage to the environment avoided, and sustainable use of natural resources ensured [2,3]. The EIA is also one of the major tools, which governments and societies worldwide rely upon for environmental management. They primarily use it to help them identify, predict, and mitigate the environmental impacts of their activities [4-6]. The EIA's main purpose is to provide information to decision makers and the public about the environmental implications of the proposed project before decisions are made. Besides providing information, it also suggests measures to prevent or reduce those impacts and mitigation plans. Overall, the EIA offers a systematic process of examination, analysis, and assessment of planned activities with a view to ensuring environmentally sound and sustainable

*Corresponding author. development [7].

International experiences indicate that political factors have been the driving forces behind the introduction and practice of EIAs [3]. The challenges for EIAs are political rather than technical. In order to make EIAs more than a ritual, changes in the attitudes and behavior of political leaders and public officials will be necessary [8]. These changes can come from a strong base in environmental policy, law, and rights. The EIA is universal, but situations do change from culture to culture. In the case of industrially advanced and particularly developing countries, even if technical and financial issues are dealt with in an appropriate manner to produce the desired results, the EIA quality will be poor without a favorable sociopolitical context for the EIA system to operate. Economic conditions and cultural influences have significant bearing on the form of an EIA system. EIAs appear to be most effective where environmental values are inte-grated into a nation's culture and its public law and policy [3]. Major contributing factors include time and money, literacy, the official language and public presentation, education, cultural differences, gender, geographical remoteness, and the political and institutional culture of decision-making. 
The recognition of problems in EIA practice has led to numerous studies providing suggestions for improvement, including an international study on the effectiveness of environmental assessments [9]. That study identified the strengthening of follow-up environmental management activities as one of the major priorities for improving EIA effectiveness. Ultimately, improving environmental management with EIAs will help ensure more environmentally acceptable development outcomes [9,10]. In addition, there are many debates in the literature about the effectiveness of EIAs. These debates focus on the factors [9] that can be advanced to explain why EIA systems are effective, on which evaluation criteria are appropriate in judging the effectiveness of an EIA system [7], and on how EIAs can be improved [11]. In 1995, Christopher Wood introduced an EIA evaluation model comprising 14 core criteria. This model has been applied in a number of developing countries including China [12], Sri Lanka [13], Pakistan [14], Malaysia, Indonesia, Thailand [15], Egypt, Turkey, Tunisia [2], Bangladesh [16], and other Mideast countries [17].

Like many other developing and developed countries of the world, in Lao PDR not all projects need to undergo EIAs, just those likely to have adverse environmental and social impacts. But the EIA does not appear to be an effective tool to safeguard the environment and socioeconomic structure of the nation's communities [18]. However, there is not much research on the functioning of the EIA system in Lao PDR. It is hard to find reference research papers on the system, except for some reports produced by international organizations [19-22]. This paper aims to fill this gap by exploring and seeking to explain the nature of the EIA procedures-practice gap in Lao PDR, and highlight the strengths and weaknesses of the Lao EIA system. The study relies on a review of the literature and on an investigation of EIA legislation, administrative procedures, guidelines, and relevant documents in Lao PDR using the development of a model proposed by Leu et al. 1996 [23]. It includes seven key criteria, with a range of supporting subcriteria ranging from full, partial, nonexistent, or not applicable. Another criterion proposed by Wood 1995 [24] has been applied to evaluate the overall performance of seven EIA systems. Finally, conclusions and recommendations are offered to further improve the EIA system and its performance.

\section{Lao PDR: Context, Institutional and Legal Basis for EIA}

\subsection{Lao PDR Background}

Lao PDR is a land-locked and mountainous country, surrounded by Cambodia, China, Myanmar, Thailand, and Vietnam. Around $70 \%$ of the country's terrain is mountainous, reaching a maximum elevation of 2820 meters in Xieng Khouang Province. Population is about 6.38 million and land area is $236,800 \mathrm{~km}^{2}$. Lao PDR is covered with a web of rivers and streams. The largest is the Mekong River, flowing 1898 kilometers from north to south, 919 kilometers of which forms the major portion of the border with Thailand. It is estimated that some $60 \%$ of all the water entering the Mekong River system originates in Lao PDR. These rivers and streams provide great potential for hydropower development as $51 \%$ of the power potential in the lower Mekong basin is within Lao PDR. The country is also one of the most biodiversity rich countries in the region. A relatively low population density and a moderate rate of natural resource exploitation relative to neighboring countries have allowed significant natural and cultivated biological resources to survive.

The Lao people are highly dependent on natural resources and the environment for their food security and livelihoods. Approximately $40 \%$ of the rural population is considered at risk of food insecurity owing to loss of access to natural resources, floods, drought, or a sudden increase in food prices. Directly and indirectly, natural resources contribute almost three quarters of per capita GDP and more than 90\% of employment in Lao PDR. Almost $60 \%$ of foreign direct investment in Lao PDR is related to natural resources. Aquatic resources account for as much as $70 \%-90 \%$ of protein intake in parts of the lowlands. Non-timber forest products (NTFPs) are estimated to make up $40 \%$ of total rural income. However, unsustainable natural resource management practices are causing significant environmental damage, and have begun to reverse this favorable situation. For example, forest resources, which once covered about $70 \%$ of total land area, had declined to $42 \%$ by 2002 . Widespread soil erosion resulting from the loss of forest cover, especially in the uplands, and shorter fallow periods have also led to declining agricultural productivity (Table 1).

\subsection{Institutional Framework for EIA in Lao PDR}

The Ministry of Science and Technology was created in 1984 and became the Science, Technology and Environment Organization (STENO) in 1993, changing in 1999 to the Science, Technology and Environment Agency (STEA) under the Prime Minister's Office. STEA became the Water Resources and Environmental Administration (WREA) in 2008, and was then upgraded into the new Ministry of Natural Resources and Environment (MONRE) in 2011 by merging WREA with parts of the National Land Management Authority (NLMA) and the Geology Department, as well as the Protection and Conservation Divisions of the Department of Forestry. The different departments and their functions and roles are still being clarified. 
Table 1. Country profile of Lao PDR.

Geography
Area
Capital
Major cities
Terrain
Climate
People
Nationality
Population
Population growth
Languages
Education
Health
Work force
Government
Type
Head of state
Prime minister
National assembly
Political parties

Administrative subdivisions

Economy

$G D P$

Per capita income

GDP growth

Natural

resources

Agriculture (29\% of GDP in 2011)

Industry (26.5\% of GDP, growth rate $4.8 \%$ in 2011)

Services

Trade

\section{$236,800 \mathrm{~km}^{2}$}

Vientiane (population approx. 800,000 in 2010)

Savanakhet, LuangPrabang, Pakse, and Thakhek

Rugged mountains, plateaus, alluvial plains

Tropical monsoon; rainy season (May to November); dry season (November to April)

Lao

6.38 million (2011)

$2.1 \%(2009-2011)$

Lao (official), English, French, and various ethnic languages

Literacy 69\%

Infant mortality rate 77.82/1.000, life expectancy 65.4 years (2009)

3.691 million; agriculture $75.1 \%$, industry $5.5 \%$, services $19.5 \%$

Communist state

Executive President Choummaly Sayasone

Thongsing Thammavong

National Judicial, district, regional, and national Supreme Court

Lao People’s Revolutionary Party (LPRP) is only legal party

16 provinces, and Vientiane

$\$ 1.105$ billion (2010)

$\$ 1010$ (2012)

7.9\% (2007), 7.2\% (2008), 7.3\% (2009), 7.5\% (2010), 7.8\% (2011)

Hydroelectric power, timber, and minerals

Primary products: Glutinous rice, coffee, maize and sweet corn, sugarcane, vegetables, tobacco, ginger, water buffalo, pigs, cattle, poultry, sweet potatoes, cotton, tea, and peanuts

Primary types: Copper, tin, gold, and gypsum mining; timber, electric power, agricultural processing, construction, garments, cement, tourism

\section{$44.5 \%$ of GDP}

Exports: $\$ 1.950$ billion in gold and copper, electricity, wood and wood products, garments, coffee and other agricultural products, rattan, and tin. Major markets: Thailand, Vietnam, China, Switzerland, United Kingdom, and Germany

Imports: \$2.258 billion. Major imports: Fuel, food, consumer goods, machinery and equipment, vehicles and spare parts. Major suppliers: Thailand, Vietnam, China, South Korea, and Belgium

Sources: http://www.adb.org/countries/lao-pdr/main, http://www.nsc.gov.la; http://unesdoc.unesco.org/images/0021/002176/217684e.pdf.

The institutional structure for environmental management in Lao PDR is characterized by: 1) national committees that guide inter-sectoral coordination among agencies; 2) national level ministries and agencies which have a core role in environmental protection and conser- vation; 3) devolution of responsibility for environmental protection from the national government to provincial and district entities; and 4) mass organizations which support the government in promoting public participation and awareness. The Government has formulated a wide 
array of legislation and regulations for environmental conservation and protection. The Environmental Protection Law (1999), supported by its Implementing Decree (2002), is the country's principal environmental legislation. It includes measures for the protection and restoration of the environment, as well as guidelines for environmental and social management and monitoring.

The Environmental and Social Impact Assessment (ESIA) Department within MONRE is responsible for overseeing the implementation of the EIA process. MONRE is responsible for issuing environmental quality standards in cooperation with the line ministries, and for issuing general EIA guidelines specifying procedures and standards to evaluate and mitigate environmental impacts caused by development projects.

Development Project Responsible Agencies (DPRAs) are sectoral ministries and other government attached agencies that are responsible for issuing screening guidelines and executing the MONRE EIA procedures.

MONRE is responsible for reviewing and approving initial environmental examination (IEE) reports, the terms of reference (TORs) for EIAs, the final full EIA reports, and the environmental management and monitoring plans (EMMPs), while the DPRAs are responsible for granting approval and issuing construction or operation license for projects.

MONRE issues environmental compliance certificates (ECCs) for projects that have successfully completed the EIA process and coordinates with line agencies (DPRAs) to carry out follow-up (compliance) monitoring and evaluation. Project proponents are required to submit regular monitoring reports to MONRE based on their EMMPs.

In addition to regulators, other parties involved in EIAs include developers, other affected parties, and facilitators. Developers, both foreign and local companies, may be with the public sector/state enterprise (e.g., Electricity du Lao PDR (EDL), national and state road authorities) or the private sector (e.g., national and multinational state enterprise companies). In either case, their projects may be subject to EIAs. Many developers have little environmental awareness and few technical or financial resources to perform EIAs. Some projects start implementation before approval, and some ignore EIAs. Public developers sometimes provide a poor example for EIA practice.

Facilitators such as consultants and legal advocates have had a relevant role in the EIA process when they have been employed by developers or project proponents. According to Lao legislation (prime minister's EIA Decree), EIAs cannot be undertaken by developer technical teams, but must be conducted only by consultant firms or by consultants registered with MONRE, and thus consultancy companies have increased their EIA activities substantially since 2000 .

Although a certification system does not exist to manage the qualifications of EIA consultants and practitioners, all consultants, international and local, wanting to qualify for carrying out EIA studies need to register with MONRE.

\subsection{EIA Legislation in Lao PDR}

Since the establishment of Lao PDR in 1975 and the adoption of a new constitution in August 1991, a number of laws and regulations have been created. The 1999 Lao Environmental Protection Law (EPL) established a framework for management of environmental resources with the objective of conserving and facilitating the sustainable use of natural resources. MONRE is responsible for EPL implementation. Other ministries issue guidelines for implementing provisions but ultimately MONRE issues environmental compliance certificates.

The basic precept of the EPL is that all persons or organizations residing in Lao PDR have an obligation to protect the environment. People or parties who damage the environment are responsible for impacts under the EPL, which stipulates that natural resources, raw materials, and energy shall be used in an economical manner to minimize pollution and waste and to allow for sustainable development (Article 5), and that all development projects and activities which potentially affect the environment shall require EIAs (Article 8). It is the obligation of all organizations to control pollution in accordance with the Environmental Quality Standards set forth in regulations by the various agencies involved (Article 22).

The first EIA regulation was issued in 2000 and upgraded into the EIA Decree in 2010, which is the most recent decree that specifies the overall principles for EIAs. It prescribes the thematic issues to be covered and the outputs expected at the different stages of the EIA process (pre-construction, construction, operation, and closure stages), and it addresses two categories of investment projects requiring environmental and social assessments:

- Category 1: Investment projects, which are small or create fewer impacts on the environment and society, and require initial environmental examinations (IEEs);

- Category 2: Large investment projects which are complicated or create substantial impacts on the environment and society, and require EIAs.

In relation to investment projects classified in Category 1 and Category 2, including projects provided for in Article 6 (2) of the EIA Decree, the project developer must first obtain an environmental compliance certificate before concluding any contracts for mining or extraction of mineral resources or for construction, before any 
business license can be issued, and before the developer can start to clear the area, start construction, or implement a project.

An IEE or EIA must be designed with after studying multiple options so that the best option can be selected. Studies must cover impacts on antiquities, culture, and custom/traditions, planning solutions for negative impacts on the environment and society, participation of the people who will be affected by the investment project and other stakeholders in discussion process at all levels, and drawing up the budget for those activities [25].

Project developers must ensure public participation and discussion with local administrators at all levels, with those who will be affected by investment projects and other persons involved in the preparation and examination of IEE reports or EIA reports.

Individuals, legal entities, or organizations desiring to render EIA services in Lao PDR must be licensed and registered with MONRE, whether they are domestic consultant firms or consultants, or foreign consultant firms or consultants already licensed to render environmental services in other countries.

Project developers are liable for accuracy of the data and information contained in their IEE or EIA reports, and they must cover every expense incurred in the process of preparing and examining of IEE reports, including measures to prevent and minimize impacts on the environment and society, EIA reports, environmental management and monitoring plans, and social management and monitoring plans, in implementing and overseeing measures to prevent and minimize environmental and social impacts, and in carrying out environmental management and monitoring plans and social management and monitoring plans.

New investment projects, which are likely to affect other investment projects, must have cumulative impact assessments, which take into account relationships with existing investment projects. If an investment project is likely to create impacts beyond national borders, a transboundary EIA must be conducted [26].

Organizations involved in the examination of (or deliberation on) IEE or EIA reports are obliged to monitor the outcomes of measures to prevent and minimize impacts on the environment and society, or the outcomes of environmental management and monitoring plans of investment projects. Meanwhile, local administrations are obliged to monitor the implementation of social management and monitoring plans.

\section{EIA Procedures in Lao PDR}

\section{Usual EIA Process}

The history of EIA implementation by the national government of Lao PDR started in 1993 with the first Na- tional Environmental Action Plan, which provided a framework for the EIA process in the country. The rather long time needed to pass and implement the legislation reflected a continuing emphasis on economic development over environmental protection. In addition to the EIA decree, government ministries are required to develop their own set of EIA procedures, standards, and guidelines.

The EIA Process in Lao PDR is determined by the Decree on Environmental Impact Assessments (No. 112/PM, 16 February 2010). The EIA process involves four basic steps: a) screening and scoping; b) preparation of the EIA report; c) review and decision-making; and d) post-project monitoring. Investment projects are divided into two categories: IEE and EIA according to the scale and type of the project. The process requirements include screening and scoping, and preparation of TORs for EIA activities before the preparation of the EIA report, and the issuance of an ECC. Figure 1 presents the project planning cycle in relation to the EIA steps that need to be implemented by the project developer, and the duties of MONRE for reviewing, monitoring, and approving the documents and activities carried out by the project developer.

For project screening, the project developer must submit an investment application to MONRE (Decree 112/PM, Article 6). The project developer must refer the list of projects for which EIAs are required, as well as consider the significance of the project's potential impacts. Based on the information provided by the project developer, MONRE decides whether the proposed project needs an IEE or an EIA.

During project scoping, the project developer prepares a scoping report and detailed TORs for the preparation of the EIA as required by Decree 112/PM (Article 11). The EIA guidelines provide guidance in Section 3 on how to prepare the scoping report and TORs. MONRE revises, comments on, and approves the scoping report and TORs before the project developer start EIA preparation.

EIA report preparation necessitates consultations with local authorities and affected people. The Public Involvement Guidelines prescribe this consultation process. Figure 2 indicates the most important steps undertaken during EIA preparation, especially in regard to public consultation. MONRE conducts an administrative and technical review of the EIA report, the environmental and social monitoring and management plan (ESMMP), and development plan. The project developer may be required to revise the EIA report, ESMMP, and development plan in order to comply with the consolidated comments provided by MONRE. Once MONRE is satisfied with the EIA report, ESMMP, and development plan, the ECC is issued with specific conditions, if required.

In Lao PDR EIAs are most commonly carried out for 


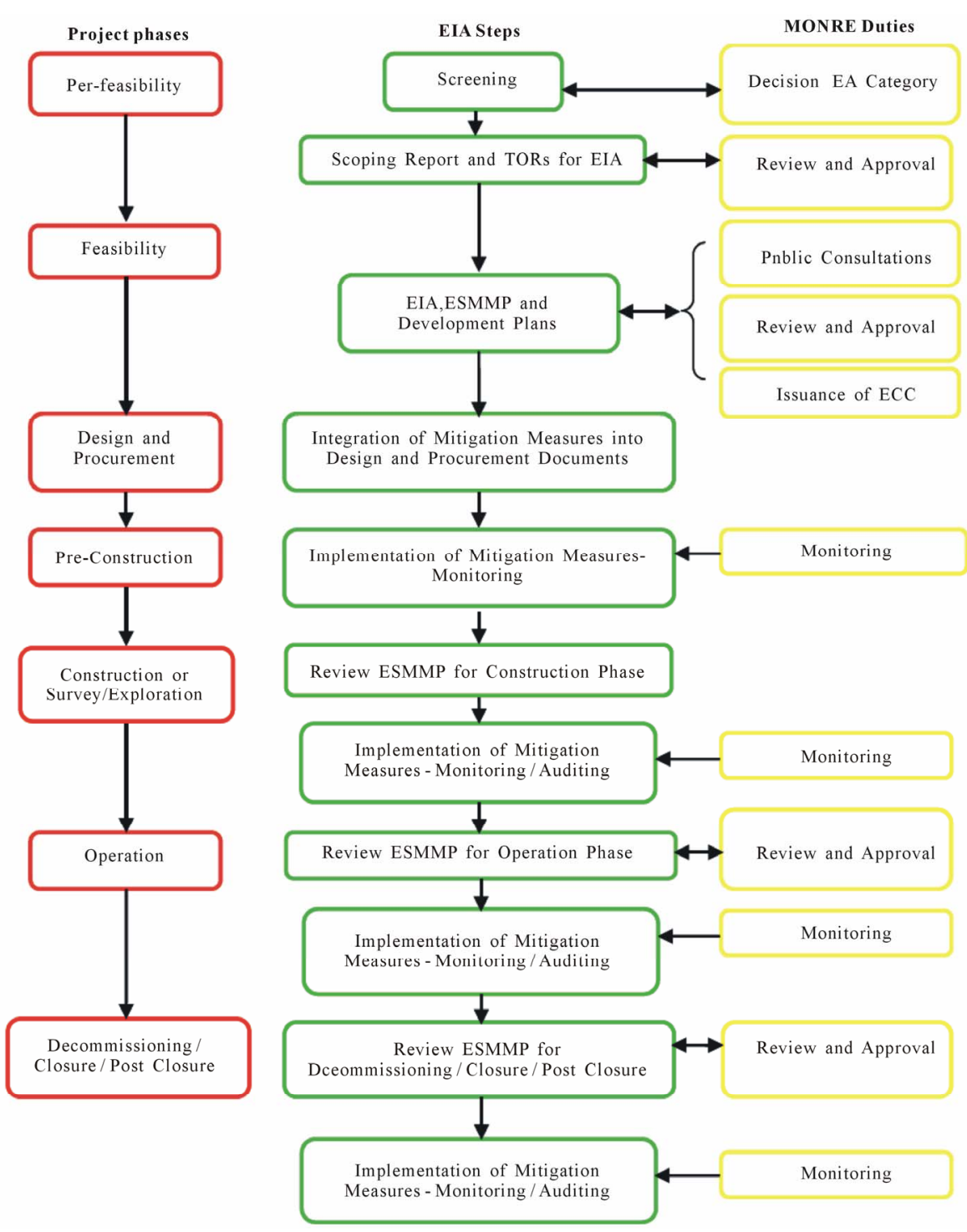

Figure 1. EIA process and the project planning cycle in Lao PDR (based on EIA guidelines, 2011) [27].

hydropower and mining activities. According to a report from the Environmental and Social Impact Assessment (ESIA) Department, 142 IEEs/EIAs were conducted from 2000 to 2011. Around 80 projects were reviewed in 2010, among them 52 IEE projects and 28 EIA projects, and ECCs were issued for only 44 projects. Unfortunately there are no comparable data to determine the total number of EIAs produced in Lao PDR.

The EIA process in Lao PDR involves a comprehensive and lengthy procedure for EIA review and appraisal, and the procedure for initiating and carrying out EIAs involves many steps. IEE reports, scoping/TORs for EIAs, and final EIA/environmental monitoring plan (EMP) reports all require the approval of DPRAs and MONRE. Depending on a project's complexity and its implications, a complete EIA procedure may take at least a year, or even more. As a consequence, in some cases the developers begin project implementation while the EIA procedure is still in progress.

\section{Results and Discussion: A Checklist Approach}

Table 2 provides an overview, with the various assessments summarized on a five-point scale from good to very deficient. Lao PDR is seen to have a reasonably good framework of environmental policy, regulations, and guidelines, but the Lao system is still lacking in good-practice guidance and has weaknesses in its EIA procedures. The quality of EIA reports is poor in terms of considering alternatives, cumulative studies, and ineffective formal channels for public participation. Further, the self-monitoring and reporting system prescribed in EMPs is rarely practiced by project proponents. In Lao PDR, 
Table 2. Summary of EIA systems performance.

\begin{tabular}{lll}
\hline Criteria & Lao PDR \\
\hline 1. & Environmental policies, regulations, and & Fair \\
guidelines & Medium \\
2. Institutional/administrative framework & Fair \\
3. EIA procedure & Fair \\
4. Roles of key actors & Deficient \\
5. Compliance of monitoring and enforcement & Medium \\
6. EIA implementation and effectiveness in & Deficient \\
7. & Availability of resources & \\
\hline
\end{tabular}

Five-point scale from good to very deficient (good, fair, medium, deficient, and very deficient). control of the EIA process is limited to EIA approval, and not many projects are monitored. Formal enforcement is also lax. Implementation is sometime difficult in Lao PDR because processes are not carried out at the appropriate time and there is some political influence. There are great variations in implementation and effectiveness among provinces, which are particularly vulnerable to political and economic pres-sures. Underpinning many of these issues is the disparity in resources for EIA activity.

Government efforts were successful in establishing competent authorities to manage the EIA process. Enforcing EIA policies and procedures requires the existence of independent bodies with adequate authority.

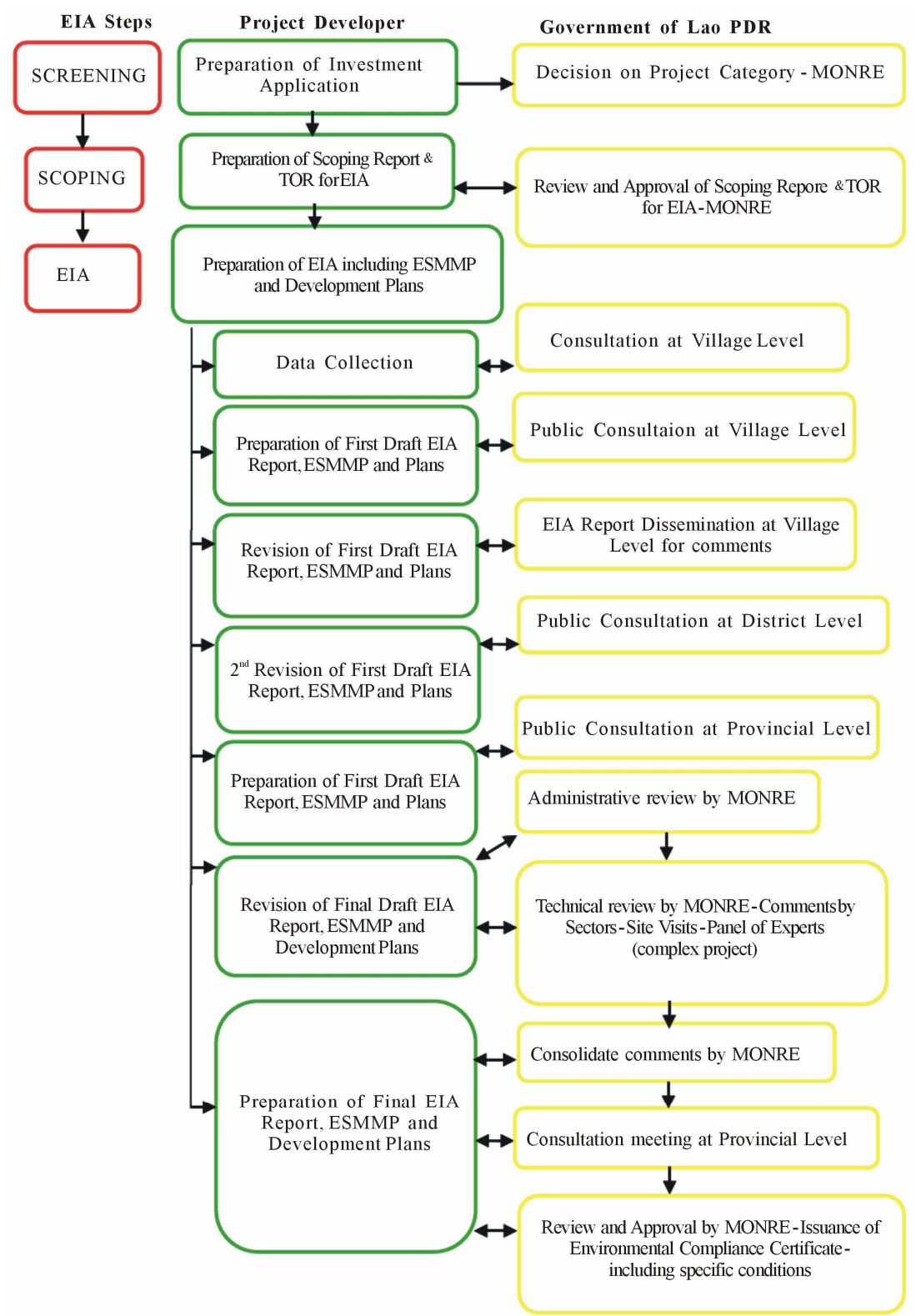

Figure 2. Responsibilities during the preparation of EIA report for projects of category 2 (based on EIA guidelines, 2011) [27]. 
Since Lao EIA authorities are understaffed and do not possess sufficient expertise, the actual enforcement and follow-up of EMMP components is likely weak. The establishment of the National Environmental and Social Committee and environmental management units is meant to help compliance monitoring, but doing so will require a sufficient number of adequately trained personnel. The current deficient monitoring is due to the lack of enforcement machinery and inadequately staffed environmental authorities. There is investment encouragement from government, since the project proponents are economically powerful and contribute substantially to improving socioeconomic conditions of project venues. The government needs to direct political will toward development but not at the cost of the environment.

We performed another evaluation (Table 3) by apply ing the 14 criteria proposed by Wood (1995) to evaluate the overall performance of seven EIA systems. The evaluation is based on the information collected from various sources, and also incorporates the authors' previous experiences, and the professional views of stakeholders revealed during informal talks and unstructured discussions through both personal interviews and email.

In Lao PDR there was a shift in national priorities concerning environmental goals as explicitly stated in official announcements. This was followed by national

Table 3. Performance of Lao PDR's systems using the evaluation criteria proposed by Wood (1995).

\begin{tabular}{|c|c|c|c|}
\hline \multicolumn{2}{|c|}{ Criteria } & \multirow{2}{*}{$\begin{array}{c}\text { Lao PDR } \\
*\end{array}$} & \multirow[t]{3}{*}{ Observations } \\
\hline 1) & Legal basis & & \\
\hline 2) & Coverage & $*$ & \\
\hline 3) & Alternatives in design & - & Very limited in Lao PDR \\
\hline 4) & Screening & * & \\
\hline 5) & Scoping & * & \\
\hline 6) & Content of EIA & $*$ & \\
\hline 7) & Review of EIA & * & \\
\hline 8) & Decision-making & $*$ & \\
\hline 9) & Impact monitoring & * & \\
\hline 10) & Mitigation & $*$ & \\
\hline 11) & $\begin{array}{l}\text { Consultation and } \\
\text { participation }\end{array}$ & * & \\
\hline 12) & System monitoring & * & Limited in Lao PDR \\
\hline 13) & Costs and benefits & - & Very limited in Lao PDR \\
\hline 14) & $\begin{array}{l}\text { Strategic Environmental } \\
\text { Assessment (SEA) }\end{array}$ & - & Just started in Lao PDR \\
\hline
\end{tabular}

Source: Adapted from Wood (1995). Legend for level of adoption/implementation of EIA practice: + fully/always; * partially/sometimes; - not/nonexistent; na, not applicable. legislation to implement EIA mandates. None-theless, the actual performance of EIA systems seems to diverge significantly from EIA objectives.

The screening process of the Lao system is linked to the various types of project activities listed in the 2010EIA decree. It defines nothing on the level of impacts, types of pollutants, or technologies as considered in other countries $[6,24]$. Similarly scoping has been left to project proponents, who submit the draft TORs but are mostly not interested in investigating diverse impacts. Inadequate involvement of stakeholders in the TOR process during scoping results in thin coverage of environmental and socioeconomic issues in the EIA reports. However, Lao PDR is now more influenced by, and receives assistance from, international donor agencies, which can be perceived to positively influence the development of the EIA process in Lao PDR.

It is increasingly recognized that public participation is crucial as an enforcement mechanism in the EIA system. The Lao EIA decree requires public participation in projects and demands that appraisal meetings or hearings be held, or that the opinions of the relevant authorities, experts and the public be obtained in some other way in the EIA preparation phase concerning plans or construction projects that may have deleterious impacts on the environment. Although legal provisions require public participation, domestic NGOs have been nonexistent in Lao PDR until recently (a new NGO regulation approved in October 2009 permits domestic NGOs to register with the government in 2010). It is usually NGOs that drum up public support for or opposition to a proposed activity. The lack of local NGO activity means that public participation in the EIA process is very limited (ADB and the Clean Air Initiative for Asian Cities (CAI-Asia) Center, 2006). However, international NGOs have at times become involved and pushed for better assessment and planning (e.g., Theun-Hinboun hydropower project and the Nam Theun 2 hydropower project).Moreover the points raised by public participants are rarely used in planning and decision-making. Hence, the effectiveness of public participation in the Lao PDR EIA system is yet to be evaluated.

In Lao PDR, there is a general absence of independent regulatory bodies (other than authorities which administer environmental management and monitoring) to assess the overall effectiveness of the EIA system, which may be an indication of inadequate awareness among decision-makers regarding the importance of follow-up and monitoring of process performance. One contributing factor may be the institutional framework within which the EIA process was established.

Although Lao PDR has defined particular report components, those components are generally weak in comparison to those in the World Bank's guidelines [28]. 
The lack of formal provisions for strategic environmental assessments (SEAs) throughout Southeast Asia can be attributed to the early developmental stage of the SEA itself [20]. However, the SEA system in Lao PDR is even newer and is grafted onto the existing EIA process, which needs to be promoted not only through legislation but also on the basis of effective EIA system enforcement.

One of the common impediments to successful EIA implementation is the limited authority of the review agency. This limitation in part arises from the relatively low status of the review agency in the government hierarchy. The review agency is a multi-tiered committee ranging from the level of provinces to that of the relevant central government ministries. It suffers from a lack of resources and technical com-petency, and the EIA approval procedure is very bureaucratic and easily derailed by political and economic pressures. These circumstances tend to debilitate legal and rational authority vis-à-vis that of other participants in EIA implementation.

Based on the 2010 World Environmental Performance Index (EPI), a rather complex and still imperfect index, Lao PDR ranks 80th out of 163 countries with an environmental performance of 59.6 out of a possible 100 . Iceland ranked $1^{\text {st }}$ with an EPI ranking of 93.5, follow by Switzerland, Costa Rica, and Sweden. This index suggests that Lao PDR must still do much to improve its environmental performance score. To a considerable extent, its lower ranking might be attributed to hasty development and the extreme land and pollution pressures that result from this. It should also be noted that this kind of database is extremely difficult to establish, and that problems exist with the comparability of data and how variables are measured.

\section{Conclusions and Recommendations}

The EIA system has strengths and weaknesses, but the problems in less-developed countries such as Lao PDR are often more acute by virtue of the human resource constraints and economic and political pressures facing the country, as well as by the inherent limitations in detailed procedures and legislation. There are marked gaps between policy and implementation, and between EIA procedures and EIA practice. Possible ways forward need to consider both the institutional framework and role of particular actors, and the EIA procedure itself.

In Lao PDR, the coordination among EIA proponents, consultants, relevant ministries, local authorities, planners, and decision-makers is generally weak. This is leading not only to inadequacies in scoping, in impact assessment, and in consideration of the concerned departments' views in EIA reports, but also to the start of developmental projects before getting EIA clearance.
Lack of coordination not only causes delay in decisionmaking, but also hinders effective implementation of environmental regulations.

Thus, most deficiencies in EIA systems can be attributed to the poor performance of foundation measures (availability of guidelines, EIA system implementation monitoring, generally weak local expertise, and inadequate training and capacity building initiatives). These measures, by definition, serve to promote good practice and underpin the successful application of systemic approaches. Hence, their absence or poor quality will negatively influence the effectiveness and robustness of EIA implementation and practices in Lao PDR.

The major difficulty faced by MONRE in effectively carrying out monitoring activities is limited institutional capacity, arising mainly from insufficiencies in the numbers of suitably qualified and experienced personnel, and in monitoring equipment and resources, as has generally been the case with environmental authorities in other developing countries $[2,13,18,29]$. The systems for implementing mitigation measures and for monitoring impacts are also ineffective.

Our analysis also indicates that there is insufficient expertise and awareness among decision-makers and the general public concerning the importance of appropriate environmental management, due to the poor enforcement of environmental legislation and EIA regulations in particular, as well as the lack of adequate monitoring programs. Clearly, this low-income country must introduced methods for improving the population's quality of life by, for example, raising literacy and creating better jobs. If the population has secured its basic requirements for maintaining an adequate lifestyle, this may increase local demands and pressure on decision-makers to account for the environmental implications of development activities.

In most developed nations, public involvement is mandatory at various EIA stages, such as screening, scoping, report preparation, and decision-making [30]. But implementation in Lao PDR's public hearings is inadequate and largely limited, particularly the involvement of domestic and international NGOs. Moreover, the points raised in public hearings are rarely incorporated in planning and decision-making. Hence, the effectiveness of public participation in the Lao EIA system is yet to be evaluated, and requires development of good guidelines for public involvement.

For all participants, the EIA database in Lao PDR is inadequate. The development of improved environmental data needs to be better managed, and data could also be exchanged among relevant sectors, local planning bodies, and consultees. Research is also needed to develop environmental impact indicators and EIA methodologies tailored to the specific conditions of Lao PDR.

The adoption of certain policies regarding the institu- 
tional aspects of EIAs would enhance their effectiveness. First, the status of the review agency in each government hierarchy level must be raised. Possible options for doing this include granting an independent ministerial status to the review agency or placing it under a more powerful ministry directly in charge of development and planning. Second, the environmental concerns of responsible agencies should be stimulated. Stricter enforcement mechanisms, environmental education for government officials, and upgrading intergovernmental mediation processes might prove useful in changing the behavior of responsible agencies. Third, EIA procedural rules must define clearly the roles of participants and their interactions.

Based on empirical knowledge, recommendations to strengthen the effectiveness of the EIA system in Lao PDR include the following:

- Strengthen integrated coordination between MONRE and relevant sectoral authorities. Better coordination at local levels is needed. The exchange of experiences between MONRE and universities and other academic institutes needs continual improvement.

- Ensuring effective public participation in the EIA system is a key component of helping to bring procedural democracy and better acceptability to decision-makers into the EIA process [31], which should be monitored by the ESIA Department working closely with the provincial and district authorities in order to foster procedural democracy. Both the scoping and review stages in the EIA process require effective consultation with regulatory authorities, stakeholders, and the public to ensure that all relevant viewpoints are taken into account throughout. The developer should incorporate the public's and stakeholders' concerns into the EIA report.

- Introduce mandatory requirements for public access to reports by affected groups, academic institutes, and NGOs; develop a central library of EIA reports. In addition, introduce a baseline data system for various components of the Lao environment; data that are held in many different government departments should be obtainable, even at some cost.

- Develop a systematic framework for EIA reviews, such as by introducing review criteria to improve the review process of EIA reports and to reduce subjectivity. A satisfactory review of an EIA should be based on multidisciplinary criteria and a process that should involve extensive consultations with specialists and concerned members of the public.

- MONRE should conduct project follow-ups and conduct site inspections during both construction and initial operation to verify whether the developer has implemented the mitigation measures described in the submitted EIA and EMMP/SMMP, as well as monitor predicted environmental impacts. These inspections are also essential to make sure that all environmental and social conditions have been satisfied. Thus, the EIA report should be an integral part of the license documentation and should be available to the ESIA Department inspectors during their frequent inspection visits. In the meantime, international development agencies such as the World Bank, ADB, UNEP, and USAID should increase their efforts to provide assistance for the institutional and procedural aspects of EIA implementation.

- Mitigation strategies should be considered both in relation to individual impacts and collectively for all impacts. Moreover, mitigation should consider technology standards such as best available technology (BAT) and best practical environmental option (BPEO). Promote research on potential innovative models that would match the requirements of the region as well as the country.

- Implement a systematic framework for consultant accreditation in order to ensure EIA best practice and to monitor the capabilities and qualifications of EIA consultants. Hence, the ESIA Department should accept EIA reports from accredited EIA consultants only.

- Environmental legislation should introduce penalties as a tool for enforcement and for encouraging compliance with environmental protection rules and requirements.

- Raise public environmental awareness and empower the public to participate actively and knowledgeably in environmental decision-making. Initiate a dialogue among concerned stakeholders in the public and private sectors. MONRE should also engage in a campaign of education through the media (radio, television, and newspapers) on the necessity of EIAs to increase the public's awareness of the concept as well as their participation in the process.

- Emphasis is needed on improving capacity building through continuous in-house training and on increasing the number of EIA professionals within MONRE and on the local level, as well as on promoting environmental awareness.

- Other improvements in EIA procedures might include mandatory scoping, with the developer presenting draft TORs to the competent authority at an early stage in the EIA process. EIA review could be improved through training and guidance on review methods. Monitoring also needs to be greatly improved, and preferably should developers to the competent authorities present mandatory, with periodic reports. It can be hoped that, with such changes, and along with the introduction of SEAs for the higher tiers of development actions, there will be some progress in reducing the procedures practice 
gap in Lao PDR. This should help to turn EIAs into the anticipatory and preliminary tool they ought to be, rather than a residual and marginal add-on to planning decisions already made on political and economic grounds and often with minimal consideration of environmental impacts.

Nonetheless, there are also some opportunities other than legal ones to improve the system, such as political support for EIAs, independent reviews, and role of NGOs and electronic media in taking public concerns into consideration. Thus, there is much hope that the EIA system in Lao PDR will be further strengthened in the near future.

\section{Acknowledgements}

The comments of Department of ESIA, MONRE, and National consulting group (NCG) teams are gratefully acknowledged. We also express our appreciation to the anonymous reviewers who gave constructive feedback.

\section{REFERENCES}

[1] G Jay, S. C. Jones, P. Slinn and C. Wood, "Environmental Impact Assessment: Retrospect and Prospect," Environmental Impact Assessment Review, Vol. 27, No. 4, 2007, pp. 287-300. doi:10.1016/j.eiar.2006.12.001

[2] B. Ahmad and C. Wood, "A Comparative Evaluation of the EIA Systems in Egypt, Turkey and Tunisia," Environmental Impact Assessment Review, Vol. 22, No. 3, 2002, pp. 213-234. doi:10.1016/S0195-9255(02)00004-5

[3] M. Elliott and I. Thomas, "Environmental Impact Assessment in Australia,” The Federation Press, Sydney, 2009.

[4] B. Dipper, C. Jones and C. Wood, "Monitoring and PostAuditing in Environmental Impact Assessment: A Review," Journal of Environmental Planning and Management, Vol. 41, No. 6, 1998, pp. 731-747

[5] B. Sadler, "Environmental Assessment in a Changing World: Evaluating Practice to Improve Performance,” Final Report of the International Study of the Effectiveness of Environmental Assessment, International Association for Impact Assessment and Canadian Environmental Assessment Agency, Ministry of Supply and Services, Ottawa, 1996.

[6] Environmental Protection Authority, "Report of the EIA Process Strengthening Workshop,” Canberra, 4-7 April 1995, EPA, Canberra, 1996.

[7] J. Glasson, R. Therivel and A. Chadwick, "Introduction to Environmental Impact Assessment,” 3rd Editon, Taylor \& Francis, London, 2005.

[8] W. Chen, K. A. Warren and N. Duan., "Incorporating Cleaner Production Analysis into Environmental Impact Assessment in China," Environmental Impact Assessment Review, Vol. 19, No. 5-6, 1999, pp. 457-476. doi:10.1016/S0195-9255(99)00023-2

[9] B. Sadler, "International Study of the Effectiveness of
Environmental Assessment: Final Report Environmental Assessment in a Changing World: Evaluating Practice to Improve Performance,” 1996.

[10] D. Hickie and M. Wade, "The Development of Environmental Action Plans: Turning Statements into Actions," Journal of Environmental Planning and Management, Vol. 40, No. 6, 1997, pp. 789-801. doi:10.1080/09640569711912

[11] R. Hirji and L. Ortolano, "EIA Effectiveness and Mechanisms of Control: Case Studies of Water Resources Development in Kenya," International Journal of Water Resources Development, Vol. 7, No. 3, 1991, pp. 154-167. doi:10.1080/07900629108722508

[12] Y. Wang, R. K. Morgan and M. Cashmore, "Environmental Impact Assessment of Projects in the People's Republic of China: New Law, Old Problems,” Environmental Impact Assessment Review, Vol. 23, No. 5, 2003, pp. 543-579. doi:10.1016/S0195-9255(03)00071-4

[13] L. Zubair, "Challenges for Environmental Impact Assessment in Sri Lanka,” Environmental Impact Assessment Review, Vol. 21, No. 5, 2001, pp. 469-478. doi:10.1016/S0195-9255(01)00081-6

[14] O. Nadeem and H. Rizwan, "Evaluation of Environmental Impact Assessment System in Pakistan,” Environmental Impact Assessment Review, Vol. 28, No. 8, 2008, pp. 562-571. doi:10.1016/j.eiar.2008.02.003

[15] J. Boyle, “Cultural Influences on Implementing Environmental Impact Assessment: In-Sights from Thailand, Indonesia and Malaysia,” Environmental Impact Assessment Review, Vol. 18, No. 2, 1998, pp. 95-116. doi:10.1016/S0195-9255(97)00082-6

[16] S. Momtaz, "Environmental Impact Assessment in Bangladesh: A Critical Review," Environmental Impact Assessment Review, Vol. 22, No. 2, 2002, pp. 163-179. doi:10.1016/S0195-9255(01)00106-8

[17] K. El-Fadl and M. El-Fadel, "Comparative Assessment of EIA Systems in MENA Countries: Challenges and Prospects,” Environmental Impact Assessment Review, Vol. 24, No. 6, 2004, pp. 553-593. doi:10.1016/j.eiar.2004.01.004

[18] B. D. Clark, A. Gilard, R. Bisset and R. Tomlinson, "Perspectives on Environmental impact Assessment," Reidel Publishing Company, Holland, 1984. doi:10.1007/978-94-009-6381-8

[19] Asian Development Bank, RETA No. 6440, “Analysis of EIA/EMP in the Greater Mekong Subregion (GMS) Countries and Identification of Gaps, Needs, and Areas for Capacity Development,” 2010.

[20] Mekong River Commission (MRC), "EIA Legislation in the Lower Mekong Basin,” 2001.

[21] Sitthivong, Koutiane and Sengdeuane Wayakone, "Status of Environmental Impact Assessment Tools in Environmental Policies and Legislations,” Asian Development Bank RETA No. 6440, 2009.

[22] World Bank, "Environmental Impact Assessment Regulations and Strategic Environmental Assessment Requirements-Practices and Lessons Learned in East and Southeast Asia,” 2006. 
[23] W. S. Leu, W. P. Williams and A. W. Bark, "Development of an Environmental Impact Assessment Model and Its Application: Taiwan Case Study," Environmental Impact Assessment Review, Vol. 16, No. 2, 1996, pp. 63-134. doi:10.1016/0195-9255(95)00107-7

[24] C. Wood, "Environmental Impact Assessment: A Comparative Review,” 1st Edition, Longman, London, 1995.

[25] Lao PDR, “The Law on Environmental Protection (ELP)," 1999.

[26] Lao PDR, "Decree on the Implementation of the EPL," 2002.

[27] Lao PDR, “Prime Minister's Decree of Environmental Impact Assessment, No 112/PM,” 2010.

[28] MONRE, "EIA Guidelines, Rontij and the Finnish Envi- ronment Institute (SYKE),” 2011.

[29] G. Werner, "EIA in Asia,” In: A. K Biswas and S. B. C. Agarwala, Eds., Environmental Impact Assessment for Developing Countries, Butterworth-Heinemann, Oxford, 1992, pp. 16-21.

[30] C. Wood, "Comparative evaluation of Environmental Impact Assessment Systems,” In: J. Petts, Ed., Handbook of Environmental Impact Assessment, Vol. 2, Blackwell, Oxford, 1999, pp. 10-34.

[31] R. Aschemann, "Environmental Assessment (EA) as a Participatory Decision Making Support Tool-Rationale and Methods of Participation in EA," In: T. B. Fischer, et al., Eds., Environmental Assessment Lectures’ Handbook, Bratislava University Press, Slovakia, 2007. 


\section{Appendix}

\section{Checklist of EIA practice in Lao PDR}

\begin{tabular}{|c|c|c|}
\hline Items & Lao PDR & Observations \\
\hline \multicolumn{3}{|l|}{ Environmental Policies, Regulations, and Guidance } \\
\hline \multicolumn{3}{|l|}{ Legal basis of EIA: } \\
\hline -Implemented through primary regulations (mandatory) & + & Clearly defined \\
\hline $\begin{array}{l}\text {-Implemented through secondary regulations (mandatory) and guidance } \\
\text { (recommended) }\end{array}$ & $*$ & Not much in Lao PDR \\
\hline -Implemented through administrative arrangements & - & \\
\hline -Implemented retrospectively & - & \\
\hline -Appeal and dispute settlement & $*$ & \\
\hline -Compliance monitoring and enforcement & $*$ & $\begin{array}{l}\text { Limited activities in Lao } \\
\text { PDR }\end{array}$ \\
\hline -Strategic environmental assessment & - & No guidelines in Lao PDR \\
\hline \multicolumn{3}{|l|}{ Requirements formally included in the EIA report scope: } \\
\hline -Defined format and contents & $*$ & \\
\hline -Proposal specific terms of reference & - & \\
\hline -Alternatives and no-action strategy & $*$ & \\
\hline -Cultural, social, and economic issues & + & \\
\hline -Impact mitigation measures & $*$ & \\
\hline -Environmental management and monitoring programs & $*$ & \\
\hline -Nontechnical summary & - & \\
\hline \multicolumn{3}{|l|}{ Complete Set of EIA guidelines from the environmental agency for: } \\
\hline -Technical guidelines for various types of development & $*$ & \\
\hline -EIA procedures (e.g., screening, scoping, impact analysis) & $*$ & \\
\hline -Public involvement and participation & $*$ & \\
\hline -EIA preparation & $*$ & \\
\hline -EIA review & $*$ & \\
\hline -Appeal & $*$ & \\
\hline -EIA compliance monitoring and enforcement & $*$ & \\
\hline -Strategic environmental assessment & - & \\
\hline -Influence of financing agencies guidelines on national EIA regulations & * & \\
\hline -Influence of international conventions on national EIA practice & $*$ & \\
\hline \multicolumn{3}{|l|}{ II. Institutional/Administrative Framework } \\
\hline Existence of a core environmental agency responsible for the development of the EIA system & + & \\
\hline \multicolumn{3}{|l|}{ EIA centralization/decentralization: } \\
\hline -A core agency and local planning authorities (LPAs) & $*$ & \\
\hline -A core agency and various regional agencies & - & \\
\hline \multicolumn{3}{|l|}{ Integration/co-ordination mechanisms for EIA implementation: } \\
\hline -Formal mechanisms established & $*$ & \\
\hline
\end{tabular}




Items
-EIA management units set up in participating agencies
-Integration of interagency participation by a core agency
-Integration of local authorities'participation by the core/regional environmental agencies
-Integration of the Statutory Consultees (SCs) by the core/regional environmental agencies
or by the local authorities
EIA review authorities' independence from project proponents
International assistance for development of core and regional environmental agencies

\section{EIA Procedure}

\section{Steps developed in the EIA procedure:}

- Screening process

- Scoping process

- EIA preparation

-Alternative analysis

-Environmental risk analysis

-Cost-benefit analysis

- Independent EIA review states

- Public proponent's response to representations

- EIA revision by proponent, based on comments to produce the final EIA.

- Publication of EIA decisions and results

- EIA review bodies have veto power over decision-making

- Formal mechanisms for appeal and dispute settlement PDR

- Clear limit for each step of EIA procedure

Formal channels for public participation in the EIA procedure:

- Prior to the EIA study (i.e. scoping, public presentation)

- During the EIA study

- After the EIA study (formal mechanisms for public notification and inspection)

- Access to the EIA

- Public audience

- Involvement in the EIA review

- Involvement in decision-making

The requirements of international financing agencies affect the national EIA procedure

\section{Role of the Key Actors Involved}

Necessary roles and responsibilities have been defined and the appropriate actors allocated to perform these tasks have been assigned:

- Independent EIA review bodies organized by responsible agencies

- Mandatory requirements for consultation with Statutory Consultees (SCs)

- Involvement of a supreme authority to resolve appeals regarding decisions on EIA cases

$-$

$-$

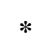

*

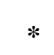

$-$

$-$

*

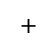

$*$

$*$
Not well in Lao PDR

Not much in Lao PDR

Limited in Lao PDR

Limited in Lao PDR

Limited in Lao PDR

\section{Limited in Lao PDR}

Limited in Lao PDR

Limited in Lao PDR

Limited in Lao PDR

Limited in Lao PDR

Sometimes in Lao PDR

- Involvement of judicial institutions to resolve appeals regarding the legal and/or administrative process of EIA

Sometimes in Lao PDR

- $\quad$ Sometimes in Lao PDR

$+$ 


\begin{tabular}{cccc}
\hline Items & Lao PDR & Observations \\
\hline Involvement of international financing agencies in domestic EIA cases & $*$ & Sometimes in Lao PDR
\end{tabular}

Involvement of international financing agencies in domestic EIA cases

Sometimes in Lao PDR

\section{EIA Compliance Monitoring and Enforcement}

EIA formal compliance monitoring programs in place:

- Carried out by the core/regional environmental agencies

- Carried out by local or other competent authorities

- Involvement of independent review bodies in the programs

- Submission of regular monitoring results by proponents

- Formal mechanism for reviewing the results of compliance monitoring

- Involvement of local communities in the program

- Public access to the results of the compliance monitoring and enforcement program

Formal enforcement of EIA decisions:

- Defined penalties/sanctions against noncompliance with EIA decisions

- Channels for public to appeal against noncompliance with EIA decisions

- Involvement of judicial institutions in EIA enforcement

- Linking with the permitting/licensing system

Involvement of international financing agencies in national compliance monitoring/enforcement

VI. EIA Implementation and Effectiveness in Practice

EIA influence in the project cycle:

- Full EIA processes are being conducted at appropriate times

- EIAs proceed in association with feasibility study

- EIAs used to justify project decisions that have already been made

- Decision-making significantly affected by the EIA results

- Projects frequently modified as a result of EIA findings

- Mitigating measures carried out satisfactorily

- EIAs used as an effective instrument of planning

Influence of political, social, and economic factors in EIAs:

- Economic growth has higher priority than environmental protection

- Political factors frequently affect decisions on EIA cases

- Public's awareness and its ability to participate in the process

- Influence of NGOs on EIA cases

Appropriate EIA approach to recent environmental issues/trends:

- Sustainable development/Agenda 21

- Use of best/clean technologies

- Social/economic impacts

- Global changes and Agenda 21

Opportunities to experiment and "learn by doing" in order to develop more appropriate and effective administration and mechanisms

Regular auditing of EIA by core agency reviews 


\begin{tabular}{|c|c|c|}
\hline Items & Lao PDR & Observations \\
\hline Regular auditing of the EIA system by the core agency or other competent authorities & - & \\
\hline $\begin{array}{l}\text { Regular assessment of the general EIA results and effectiveness by an independent board or } \\
\text { national council (based on evidence of monitoring, audits, etc.) }\end{array}$ & - & \\
\hline Strategic environmental assessment (SEA) formally implemented & $*$ & Limited in Lao PDR \\
\hline Influence of international NGOs on domestic EIA decisions & - & \\
\hline Influence of international pressures and criticisms on national EIA practice & * & Limited in Lao PDR \\
\hline \multicolumn{3}{|l|}{ VII. Availability of Resources } \\
\hline \multicolumn{3}{|l|}{ Extensive commitment of governmental staff to implement EIA: } \\
\hline - At central level (core/regional agencies) & * & \\
\hline - At local level & - & \\
\hline - Regular EIA training courses organized/coordinated & * & \\
\hline $\begin{array}{l}\text { - Database of subject experts in place, from which experts could be called upon for } \\
\text { consultation }\end{array}$ & - & \\
\hline \multicolumn{3}{|l|}{ Adequate measures in place for upgrading human resources outside the government: } \\
\hline $\begin{array}{l}\text { - Training courses organized by the core/regional environmental agencies available to } \\
\text { consultants, proponents, or NGOs }\end{array}$ & $*$ & Sometimes in Lao PDR \\
\hline $\begin{array}{l}\text { - Training courses organized by nongovernmental institutions available to consultants, } \\
\text { proponents, and NGOs }\end{array}$ & $*$ & Sometimes in Lao PDR \\
\hline - Existence of a consultant registration system & $*$ & Sometimes in Lao PDR \\
\hline - Database of consultants established for reference & - & \\
\hline - Periodic notices and publicity of good EIA practice performed by consultants and proponents & - & \\
\hline \multicolumn{3}{|l|}{ Adequate physical resources for EIA implementation: } \\
\hline - Central environmental database established & * & Limited in Lao PDR \\
\hline - EIA tracking system established & - & \\
\hline - Central database of EIA reports established & $*$ & Limited in Lao PDR \\
\hline - Regular EIA status reports or newsletters published by core/regional environmental agencies & - & \\
\hline - Use of GIS in EIAs and national/regional planning by governmental agencies & * & Limited in Lao PDR \\
\hline - Access to the aforesaid facilities by the public and NGOs & - & \\
\hline Availability of international technical supports (e.g., advisorship, EIA training) & $*$ & Sometimes in Lao PDR \\
\hline Availability of international financial supports (e.g., the development of EIAs and facilities) & * & Sometimes in Lao PDR \\
\hline
\end{tabular}

Legend for level of adoption/implementation of EIA practice: + Fully/always; * Partially/sometimes; - Nonexistent; na Not applicable. 